\title{
Article \\ Kinetic Study on Microwave-Assisted Oligomerization of 1-Decene over a HY Catalyst
}

\author{
Snunkhaem Echaroj ${ }^{1}\left(\mathbb{D}\right.$, Channarong Asavatesanupap ${ }^{1}$, Sumaeth Chavadej ${ }^{2,3}$ and Malee Santikunaporn $4, *$ (I) \\ 1 Department of Mechanical Engineering, Faculty of Engineering, Thammasat School of Engineering, \\ Thammasat University, Bangkok 12120, Thailand; snunkha@engr.tu.ac.th (S.E.); acharnna@engr.tu.ac.th (C.A.) \\ 2 The Petroleum and Petrochemical College, Chulalongkorn University, Bangkok 10330, Thailand; \\ Sumaeth.C@chula.ac.th \\ 3 Center of Excellence on Petrochemical and Materials Technology, Chulalongkorn University, \\ Bangkok 10330, Thailand \\ 4 Department of Chemical Engineering, Faculty of Engineering, Thammasat School of Engineering, \\ Thammasat University, Bangkok 12120, Thailand \\ * Correspondence: smalee@engr.tu.ac.th
}

Citation: Echaroj, S.;

Asavatesanupap, C.; Chavadej, S.; Santikunaporn, M. Kinetic Study on Microwave-Assisted Oligomerization of 1-Decene over a HY Catalyst. Catalysts 2021, 11, 1105. https:// doi.org/10.3390/catal11091105

Academic Editor: Anton Naydenov

Received: 13 August 2021

Accepted: 12 September 2021

Published: 14 September 2021

Publisher's Note: MDPI stays neutral with regard to jurisdictional claims in published maps and institutional affiliations.

Copyright: (c) 2021 by the authors. Licensee MDPI, Basel, Switzerland. This article is an open access article distributed under the terms and conditions of the Creative Commons Attribution (CC BY) license (https:// creativecommons.org/licenses/by/ $4.0 /)$.

\begin{abstract}
A promising production route for a high-quality base stock for lubricants is the oligomerization of high molecular-weight olefins in a high energy efficiency system. Oligomerization of 1-decene $\left(C_{10}\right)$ was conducted in a microwave-assisted system over a HY zeolite catalyst at different reaction temperatures and times. Higher reaction temperature resulted in increasing formation of dimers and trimers. The oligomerization reaction yielded $80 \%$ conversion, $54.2 \%$ dimer product, $22.3 \%$ trimer product and $3.4 \%$ heavier product at $483 \mathrm{~K}$ for a reaction time of $3 \mathrm{~h}$. The best fit kinetic model for the dimerization reaction was formulated from an assumption of no vacant reaction sites. For the trimerization reaction, a molecule of dimer $\left(C_{20}\right)$ formed on the active site, interacted with a molecule of 1-decene in the bulk solution to form a molecule of trimer $\left(C_{30}\right)$. Apparent activation energies for the dimerization and trimerization reactions were $70.8 \pm 0.8$ and $83.6 \pm 0.9 \mathrm{~kJ} / \mathrm{mol}$, respectively. The $\mathrm{C}^{13}$-NMR spectrum indicated that the oligomer product contained a significant portion of highly branched hydrocarbons, causing a substantial reduction in the viscosity index compared to conventional poly-alpha olefin lubricant (PAO).
\end{abstract}

Keywords: oligomerization; micro-kinetic modelling; zeolite; $\mathrm{C}^{13}$-NMR; microwave-assisted

\section{Introduction}

A lubricant base stock with high thermal stability is crucial to achieve long-term machinery performance, especially for military equipment, aircraft and heavy-duty internal combustion engines that operate under harsh environmental conditions. Over the last decade, synthetic-type lubricant base stocks have dominated this high-end application. Synthetic lubricants belonging to the poly-alpha olefin (PAO group IV) have higher retail costs but offer more effective performance than other groups of lubricants, with better thermal stability and longer oil change intervals. However, current production technology of synthetic-type lubricants is based on the oligomerization of ethylene which is produced from petroleum oil by an energy-intensive process, known as steam cracking, causing high production costs. Ethylene also exists in a gaseous state, and expensive facilities are needed to prevent gas leakage. Long chain alkenes, especially 1-decene can be used to produce synthetic lubricant base stock. 1-Decene can be prepared from 1-decanol derived from the hydrogenation of fatty acids of renewable vegetable oils [1]. 1-Decene is also in a liquid state and much easier to handle compared with ethylene gas.

Oligomerization is a chemical reaction whereby olefin molecules combine to form higher molecular-weight compounds. The reaction mechanism of oligomerization is dependent on the characteristics of applied catalysts such as Ziegler-Natta or metallocene 
to propagate the reactant molecules through the insertion of monomers into the vacant orbit sites of the transition metal catalysts [2]. In Lewis acid catalysis, oligomerization is activated by a hydrogen donor agent such as water, called cationic oligomerization [3]. Other agents for oligomerization include heterogeneous acid catalysts such as sulfatedalumina [1], tungsten-zirconia [4] and zeolite [5] that are cheaper than other types of catalysts. One important feature of zeolite catalysts is that their inner structure can be manipulated to tailor products [6,7], while spent zeolite catalysts can be simply regenerated via chemical or thermal treatment [8]. The type of catalyst used has been found to affect the properties of lubricant product obtained via oligomerization reaction [9]. Significant properties used to benchmark different lubricant products are viscosity, viscosity index and pour point [10]. The price of lubricant is also related with these properties. For instance, a lubricant with a higher viscosity index is more expensive than another lubricant with a lower viscosity index. This is because the higher viscosity index, the higher the thermal stability of a lubricant oil [11]. However, an increase in viscosity index also results in an increase in pour point temperature, causing a serious problem in use under an extremely cold weather condition. Pour point temperature is the lowest temperature, at which that particular liquid sample still remains in liquid form before turning into a solid state at a temperature lower than the pout point [12].

Oligomerization over a zeolite catalyst is generally performed in a fixed-bed reactor with conventional heat [13]. Several studies have investigated oligomerization in terms of kinetics to gain a better understanding of the reaction mechanism and formulate mathematical models to predict the oligomerization reaction concerning reactants and catalyst characteristics. Recently, intensification processes for several reactions, especially under microwave irradiation, have attracted increasing interest due to several advantages such as fast heating rate and high heating efficiency [14]. Mahajani and Kamal (2020) formulated microkinetic equations for the oligomerization of aldehyde over cation exchange resins. Their experimental data fitted well with the Langmuir-Hinshelwood-Hougen-Watson (LHHW) model, indicating that the adsorption rate of the reactant was proportional to the concentration of vacant sites [15-18]. Another unique characteristic of zeolite catalyst is the formation of branch molecules from the isomerization reaction that causes reduction of the product pour point [19]. Oligomerization reaction kinetics were controlled by the acid sites of the catalyst, while the formation of branch molecules increased with increasing concentration of acid sites on the catalyst [20]. Deactivation of the zeolite catalysts after the reaction is a serious issue that has been intensively studied over the last decade. Both soft and hard cokes commonly occur during chemical reactions over heterogeneous acid-catalysts, whereas the soft coke involves deactivation of the catalyst. The soft coke can be effectively removed by thermal treatment at 473-673 K under nitrogen gas [21]. Accumulation of hard coke inside zeolite micropores exhibits a long-term negative effect on catalyst performance and this can be oxidatively removed only at a high temperature of $773 \mathrm{~K}$ [22]. To the best of our knowledge very little research work was performed to investigate the impact of microwave irradiation on the oligomerization reaction.

Thus, here, to develop a more sustainable chemical process, oligomerization of 1decene over a HY zeolite catalyst was proposed to produce a lubricant base stock using microwave irradiation to supply thermal energy for the oligomerization reaction. The kinetics of both dimerization and trimerization from 1-decene over a HY zeolite catalyst under microwave irradiation were investigated. The results could offer new perspective on the shift in reaction mechanism as reaction temperature changes. Experimental data were used to verify the proposed microkinetic behaviors of the 1-decene oligomerization reaction over a HY zeolite catalyst. Activation energy of the oligomerization reaction was also calculated, while the $\mathrm{C}^{13}$-NMR technique was employed to determine the chemical structure of all produced oligomers. 


\section{Results and Discussion}

\subsection{Effect of Temperature on Oligomer Product Composition}

Figure 1 shows the process performance of the oligomerization reaction in terms of 1-decene conversion and product composition profiles with time at three different temperatures $(423,443$ and $483 \mathrm{~K}$ ) over the HY zeolite catalyst under microwave irradiation. As shown in Figure 1a, for any given reaction temperature, the conversion of 1-decene increased with time and reached a maximum level at high reaction time. For any given reaction time (lower than $120 \mathrm{~min}$ ), an increase in reaction temperature significantly enhanced the conversion of 1-decene. This result corresponded well with our previous investigation on the 1-decene oligomerization [4,5]. The higher the reaction temperature, the shorter the reaction time to reach the highest conversion of 1-decene. Highest conversion of 1-decene at $423 \mathrm{~K}$ with reaction time greater than $150 \mathrm{~min}$ was $58.5 \%$. Conversion increased to around $82 \%$ when reaction temperature increased from 423 to $443 \mathrm{~K}$. With further increase in reaction temperature from 443 to $483 \mathrm{~K}$, maximum conversion of 1-decene appeared unchanged. As shown in Figure 1b, 1-decene concentrations for all three reaction temperatures exhibited opposite trends to 1-decene conversions, as explained later by the activation energy values.

Figure 1c illustrates the percentage of dimer $\left(C_{20}\right)$ produced from 1-decene over the HY zeolite catalyst at different reaction temperatures and reaction times. The dimerization reaction increased with increasing reaction temperature from 423 to $443 \mathrm{~K}$. However, dimer percentage at reaction temperature of $483 \mathrm{~K}$ was lower than at reaction temperature of $443 \mathrm{~K}$ when reaction time exceeded $80 \mathrm{~min}$. This occurred because the conversion of dimer to trimer $\left(C_{30}\right)$ increased with increasing reaction temperature. Results indicated that the optimum reaction temperature for dimer production was around $443 \mathrm{~K}$. Most diesel oils contain $\mathrm{C}_{20}$ as the main fraction because the heating value of $\mathrm{C}_{20}$ is in a suitable range for internal diesel combustion engines.

The profiles of trimer $\left(\mathrm{C}_{30}\right)$ and heavier products (mostly $\left.\mathrm{C}_{40}\right)$ via the oligomerization reaction from 1-decene over the $\mathrm{HY}$ zeolite catalyst as a function of reaction temperature and reaction time are shown in Figure 1d,e, respectively. Concentrations of both products increased at higher reaction temperature and longer reaction time. At reaction time longer than $180 \mathrm{~min}$ for all reaction temperatures, concentrations of both trimer and $\mathrm{C}_{40}$ products reached maximum levels. Highest trimer content $(23 \%)$ was obtained at reaction temperature $483 \mathrm{~K}$ and reaction time $80 \mathrm{~min}$. Rapid increase in trimer content was observed at reaction time from 20 to $120 \mathrm{~min}$. Proper fractions of trimer and $\mathrm{C}_{40}$ are necessary for the formulation of lubricant oil products. Fractions of trimer and $\mathrm{C}_{40}$ that are too high can cause high viscosity of lubricants that exceeds permitted limits for diesel engines. Results found here concurred with a previous study [23].

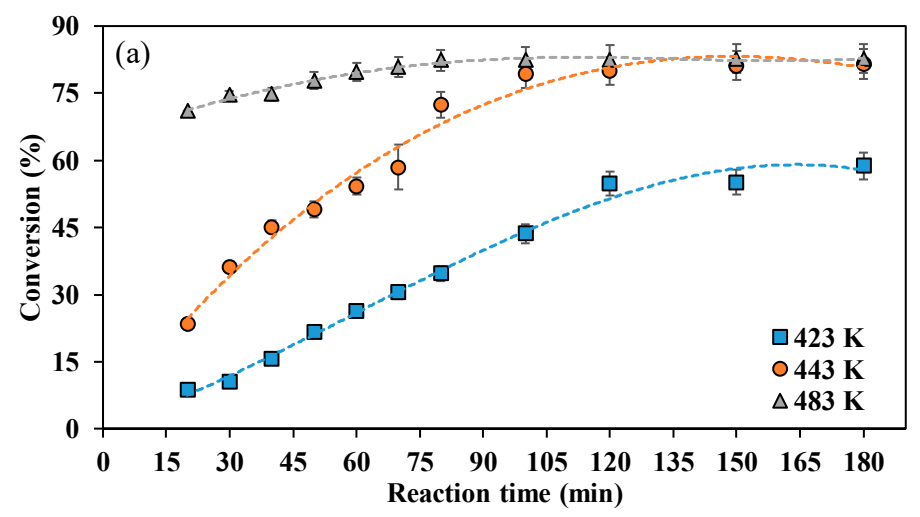

Figure 1. Cont. 

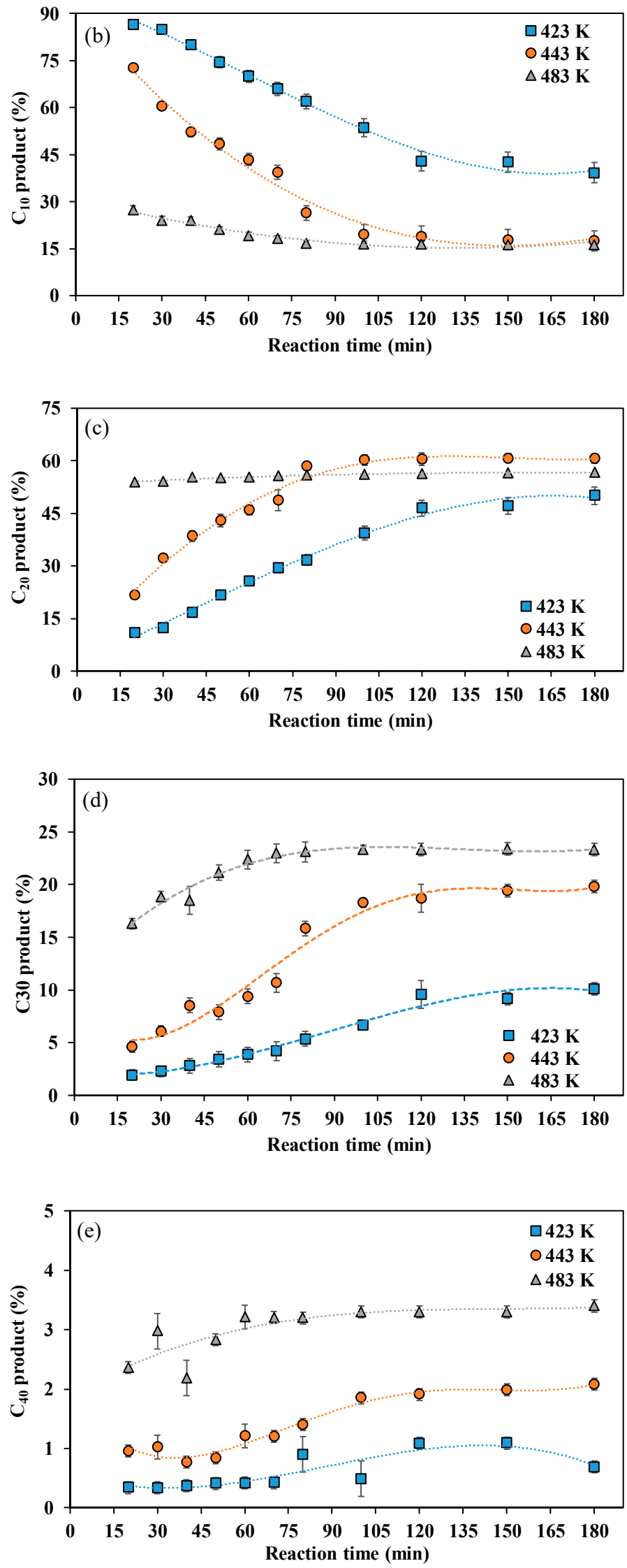

Figure 1. Effects of reaction temperature and reaction time on (a) 1-decene conversion; (b) $\mathrm{C}_{10}$ content; (c) $\mathrm{C}_{20}$ content; (d) $\mathrm{C}_{30}$ content and (e) $\mathrm{C}_{40}$ content (operating conditions: $50 \mathrm{~mL}$ 1-decene, $5 \mathrm{~g}$ HY catalyst and $1 \mathrm{~atm})$. 
The Arrhenius equation was used to find the activation energy of the oligomerization reaction over the HY zeolite catalyst under microwave radiation. The rate of reaction was calculated from the production rate of dimer and trimer found by taking derivative of the dimer and trimer as a function of reaction time. The activation energy of the oligomerization of 1-decene over the HY zeolite catalyst was calculated from the slope of the Arrhenius plot, as shown in Figure 2. The y-intercept of the plot represented the pre-exponential factor. Calculated activation energy values were $70.8 \pm 0.8 \mathrm{~kJ} / \mathrm{mol}$ for the dimerization reaction and $83.6 \pm 0.9 \mathrm{~kJ} / \mathrm{mol}$ for the trimerization reaction. These values were lower than for the oligomerization of isoamylene over acidic resin catalysts $[24,25]$ and a H-MRI zeolite catalyst [26]. Activation energy value of the ethylene oligomerization reaction over a Chevron Phillips catalyst was reported as $99.1 \mathrm{~kJ} / \mathrm{mol}$ [25], and very close to the calculated values in this study. Activation energies of $21 \pm 0.5$ and $33 \pm 0.6 \mathrm{~kJ} / \mathrm{mol}$ for the dimerization and trimerization of 1-decene over a tungsten-zirconia catalyst were lower than results in this study, corresponding to higher concentration of acidity on the tungsten-zirconia catalyst surface compared with the zeolite catalyst $[4,27,28]$. Lower activation energy can also result from a reaction where the reactants have lower stability than the product [29].

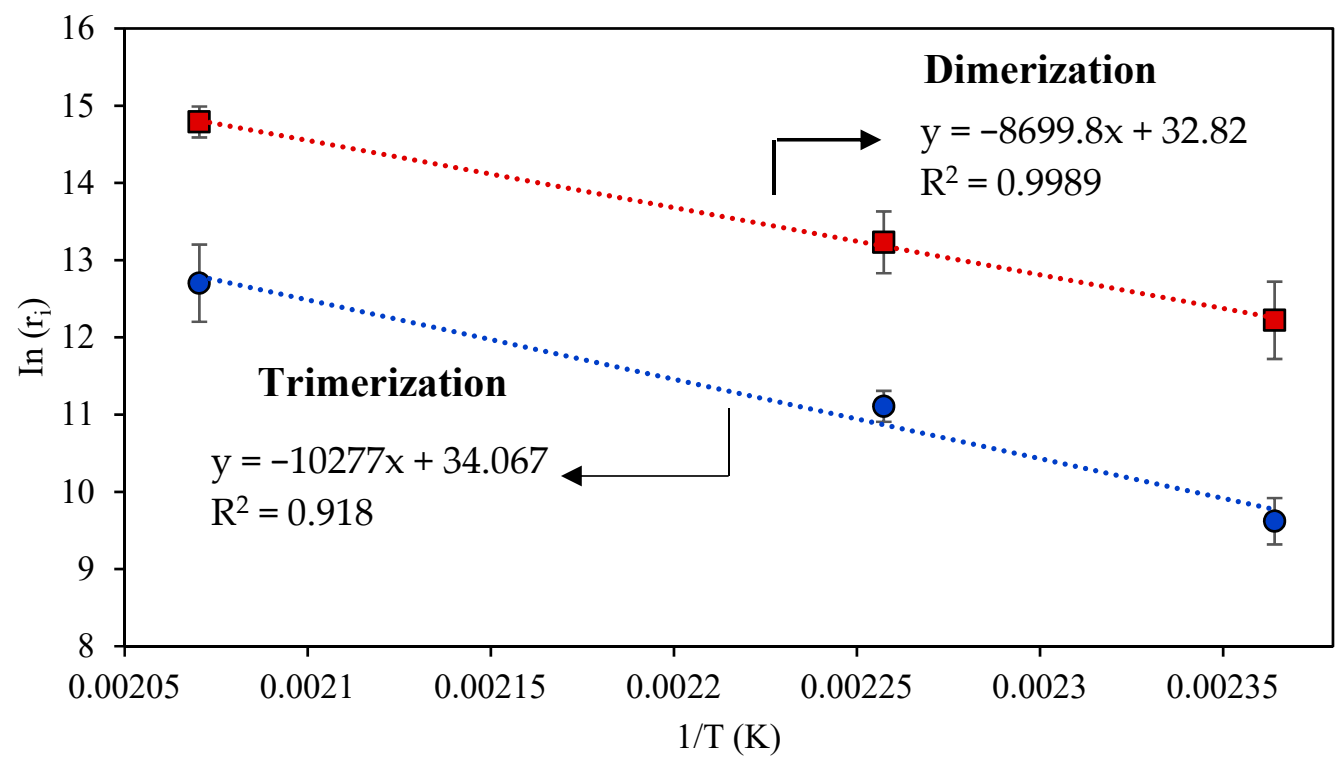

Figure 2. The Arrhenius plot to calculate the activation energy for the microwave assisted oligomerization reaction of 1-decene over the HY zeolite catalyst.

\subsection{Oligomer Product Characterization Results}

Figure 3a demonstrates the $\mathrm{C}^{13}$-NMR spectrum of the oligomer product sample obtained from the oligomerization experiment at reaction temperature of $483 \mathrm{~K}$ and reaction time of $180 \mathrm{~min}$, compared to those of standard linear hydrocarbons consisting of 15 to 18 carbon atoms and a conventional poly-alpha olefin lubricant (PAO). As shown in Figure $3 b$, five peaks represent the backbone of the linear hydrocarbon structure at chemical shifts of 14.1, 22.9, 29.4, 29.9 and $32.0 \mathrm{ppm}$. Figure $3 \mathrm{c}$ shows the $\mathrm{C}^{13}$-NMR spectrum of a conventional PAO, indicating the presence of several short and long branching chains of hydrocarbons. As shown in Figure 3a, the liquid product sample obtained from this investigation contained a significant number of branched hydrocarbons, as indicated by the peaks located at 10.7, 19.8, 27.1, 37.0 and $37.5 \mathrm{ppm}$, with the longest branched structure at $10.7 \mathrm{ppm}$. Calculated values of the branching ratio and short-chain percentages of the oligomer product sample in this study and those of PAO are compared in Table 1. Increases in branching ratio and short-chain branched hydrocarbons were observed in the oligomer product sample compared to the PAO. Viscosity indices of the oligomer product and the PAO lubricant correlated well with the number of short-chain branching 
hydrocarbons. An increase in the content of short-chain branching hydrocarbons derived from the isomerization reaction resulted in reduction of the viscosity index, causing lower thermal stability of the lubricant product $[30,31]$
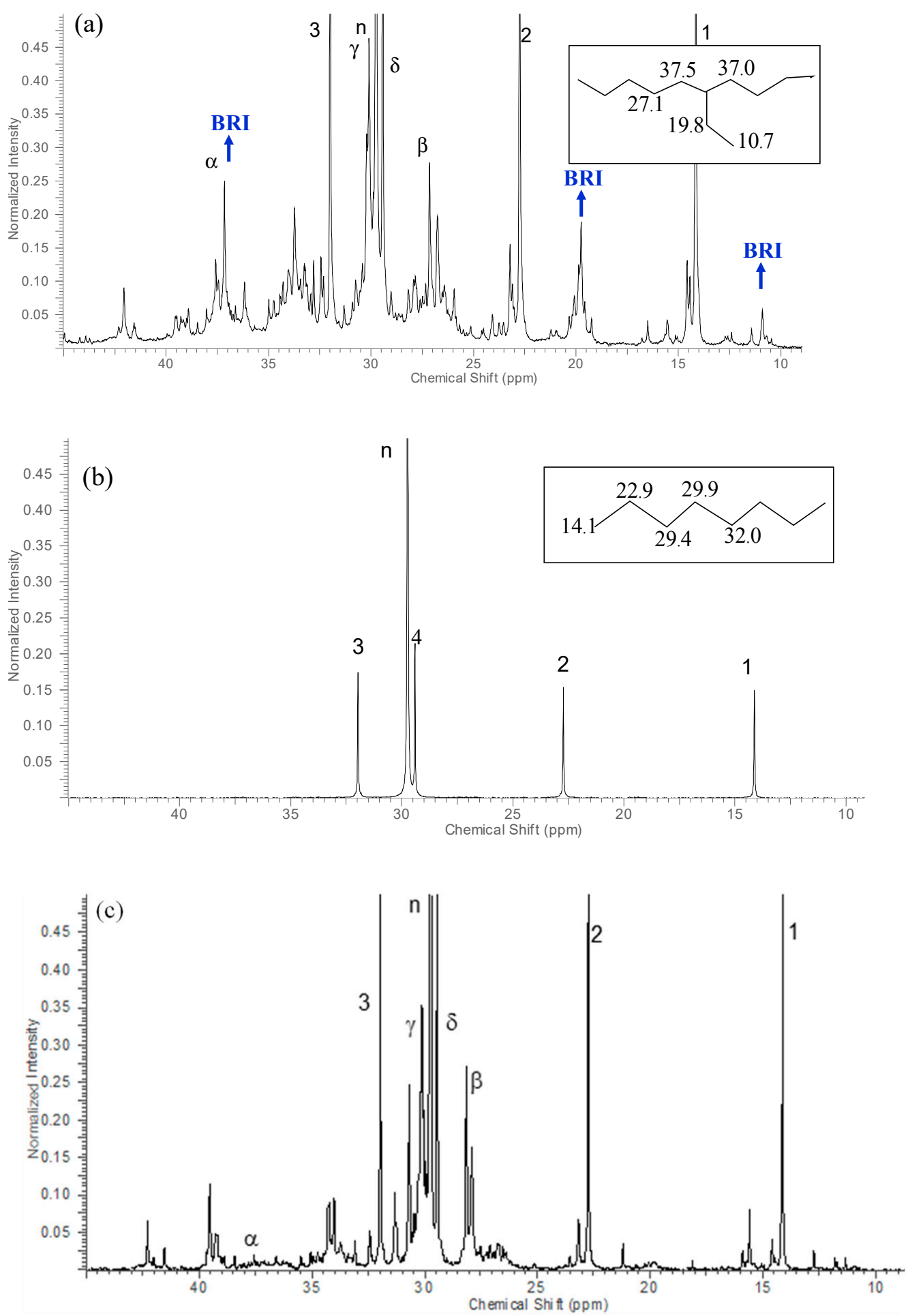

Figure 3. The $\mathrm{C}^{13}$-NMR spectrum of (a) the oligomer product obtained from the oligomerization experiment operated at a reaction temperature of $483 \mathrm{~K}$ and a reaction time of $180 \mathrm{~min}$, (b) standard linear hydrocarbons in the range of $C_{12}$ to $C_{18}$ and (c) a conventional poly-alpha-olefin lubricant oil (PAO) where BRI is a branch hydrocarbon at any carbon location. 
Table 1. Branching properties from $\mathrm{C}^{13}-\mathrm{NMR}$ analysis and viscosity index (VI) of the liquid product obtained from the experiment at a reaction temperature of $483^{\circ} \mathrm{C}$ and a reaction time of $150 \mathrm{~min}$, compared to the conventional PAO.

\begin{tabular}{ccccccc}
\hline Sample & $\begin{array}{c}\text { 11-17 ppm } \\
\text { Integral }\end{array}$ & $\begin{array}{c}\text { 18-44 ppm } \\
\text { Integral }\end{array}$ & $\begin{array}{c}\text { Short-Chain Methyl } \\
\text { Integral }\end{array}$ & $\begin{array}{c}\text { Branching } \\
\text { Ratio }\end{array}$ & $\begin{array}{c}\text { Short-Chain Branching } \\
\text { (\%) }\end{array}$ & $\begin{array}{c}\text { VI } \\
\text { Oligomer product } \\
\text { (this study) }\end{array}$ \\
3.1 & 27.1 & 1.45 & 0.11 & 46.8 & 111.5 \\
Conventional PAO & 4.3 & 43.4 & 1.5 & 0.10 & 35.1 & 123.7 \\
\hline
\end{tabular}

\subsection{Kinetic Modeling Results}

The $\triangle \mathrm{AIC}$ values of all developed kinetic equations for the dimerization and trimerization reactions are compared in Figures S1 and S2, respectively. The lower the $\triangle$ AIC value, the better the validity of a developed kinetic model, while zero value of $\triangle \mathrm{AIC}$ indicates the absolute best fit condition. Generally, any formulated kinetic model is acceptable as long as the value of $\triangle \mathrm{AIC}$ is below 4 . Values of $\triangle \mathrm{AIC}$ greater than 4 result in unreasonable kinetic constants, with high variance and wide standard deviation [32,33].

According to the lowest $\triangle \mathrm{AIC}$ value corresponding to the best fit model, $R_{D, 2.1}$ was the best kinetic model, reflecting dominance of the dimerization reaction at reaction temperature of $423 \mathrm{~K}$ and neglecting the vacant sites. This result was in good agreement with a previous investigation [34]. Increase in temperature beyond $423 \mathrm{~K}$ resulted in a significant increase in the reaction rate of trimerization, as previously mentioned. At reaction temperature of $443 \mathrm{~K}$, the best fit model was $R_{D, 2.3}$, confirming that the concentration of vacant sites on the catalyst was negligible. The dimer adsorption equilibrium was also omitted from the kinetic model equation. At reaction temperature of $483 \mathrm{~K}$, the best fit model was $R_{D, 1.1}$, also confirming that the higher the reaction temperature, the higher the activity of trimerization at the expense of dimerization. It was not physically possible for the oligomerization reaction to proceed with a relatively large number of vacant sites at high temperature because increasing temperature promoted the formation rate of the trimer. The trimer had high affinity toward an acidic site, resulting in rapid vacant site attachment to subsequently form coke [35]. Therefore, the reaction model of $R_{D, 2.3}$ was reasonable to use instead of the $R_{D, 1.1}$ model due to a low $\triangle$ AIC value of 1.34. The effect of reaction temperature in this investigation was in good agreement with previous research [4]. Significant reduction in the dimer adsorption equilibrium constant was also observed in previous research [4] as reaction temperature increased beyond $423 \mathrm{~K}$. The selected kinetic model for the dimerization reaction of decene is shown in Equation (1).

$$
R_{D}=\frac{k_{D, 2.1} K_{D E, A} C_{D E}^{2}}{K_{D E, A} C_{D E}+K_{D M, A} C_{D M}+K_{T M, A} C_{T M}} ; K_{D M, A}=0, T \geq 443 K
$$

At reaction temperature of $423 \mathrm{~K}$, trimerization proceeded via the reaction between an adsorbed dimer and an un-adsorbed molecule of 1-decene ( $R_{T, 3.2}$ model). The best fit model at this reaction temperature also suggested that the adsorption of trimer should be omitted. All other proposed models were invalid because of high values of $\triangle \mathrm{AIC}$, as shown in Figure S2. Increase in reaction temperature to 443 and $483 \mathrm{~K}$ resulted in greater trimer formation. As more trimers were generated from the trimerization reaction, their adsorption behavior on the catalyst could no longer be neglected. The best fit models of $R_{T, 3.1}$ at $443 \mathrm{~K}$ and $R_{T, 4.1}$ at $483 \mathrm{~K}$ were derived from the assumption of interaction between the adsorbed dimer and 1-decene in the presence of the vacant sites. These models also included all the adsorption equilibrium constants. For reaction temperature of $483 \mathrm{~K}$, the $R_{T, 4.1}$ model that shifted in the reaction mechanism suggested that at a very high temperature, active vacant sites should be neglected in a mathematical equation. At high temperature, the rapid deposition of trimer molecules on active sites resulted in the formation of coke cluster, leading to permanent loss in free vacant sites [36]. Consequently, the number of free vacant sites could be eliminated from the formulated equation. The 
selected kinetic model for the trimerization reaction of decene is shown in Equation (2). The formation of soft and hard coke on the spent catalyst at $483 \mathrm{~K}$ are revealed by two regions by using TGA technique, as shown in Figure 4. The first sharp drop in weight loss (Region I) of approximately $30 \%$ of the spent catalyst with increasing reaction temperature from 473 to $523 \mathrm{~K}$ was due to the increasing decomposition of soft coke. The second weight loss (Region II) of $20.8 \%$ with increasing temperature from 523 to $823 \mathrm{~K}$ indicated the decomposition of hard coke. The deposition of hard coke usually associates with the permanent deactivation of a particular site.

$$
R_{T}=\frac{k_{T, 4.1} K_{D M, A} C_{D M} C_{D E}}{1+K_{D E, A} C_{D E}+K_{D M, A} C_{D M}+K_{T M, A} C_{T M}} ;\left\{\begin{array}{c}
K_{T M, A}=0, T \leq 423 K \\
K_{T M, A} C_{T M} \gg 1, T \geq 483 K
\end{array}\right.
$$

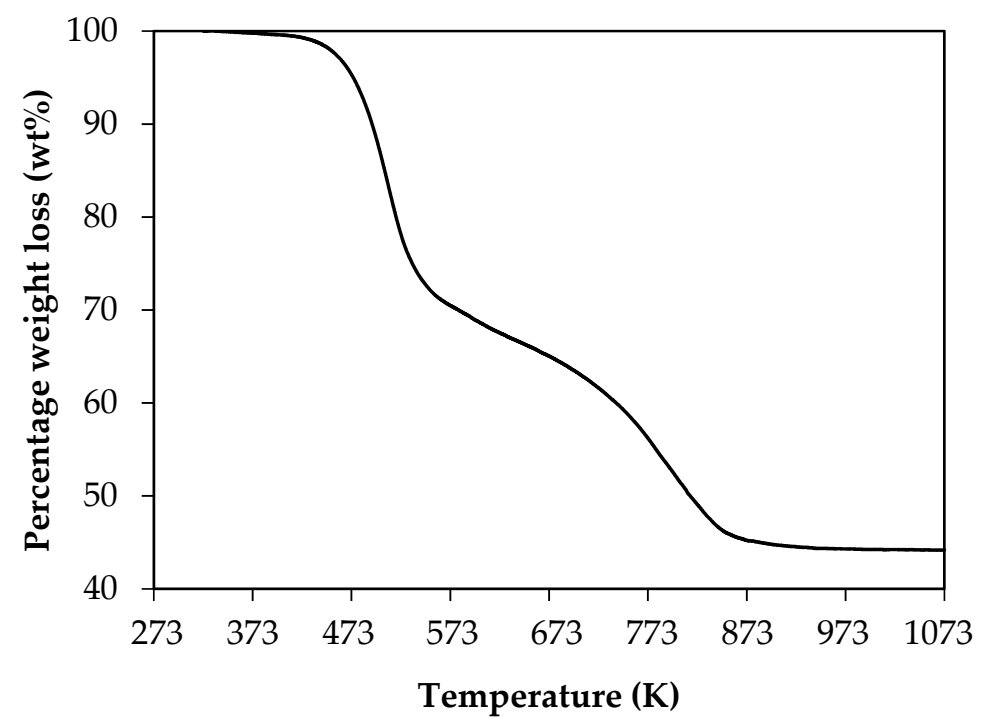

Figure 4. Decomposition of spent HY catalyst at $483 \mathrm{~K}$ based on TGA method.

Table 2 displays all values of rate constants and adsorption equilibrium constants using the non-linear regression technique. The kinetic rate constants of oligomerization over the HY zeolite catalyst in this experiment were relatively lower than those of oligomerization over a tungsten-zirconia catalyst [4]. The adsorption equilibrium constant represented the forward and backward rate constants. The dimerization reaction demonstrated relatively higher adsorption equilibrium constants compared with the trimerization reaction.

Table 2. Kinetic constant values derived from the non-linear regression method of the best-fit kinetic models.

\begin{tabular}{|c|c|c|c|c|}
\hline Kinetic Constant & Unit & $423 \mathrm{~K}$ & $443 \mathrm{~K}$ & $483 \mathrm{~K}$ \\
\hline \multicolumn{5}{|c|}{ Dimerization reaction: } \\
\hline$k_{D, i . j}$ & $\mathrm{~L} \mathrm{~mol} \mathrm{~s}^{-1}$ & $0.0002 \pm 0.000$ & $0.0001 \pm 0.000$ & $0.1611 \pm 0.003$ \\
\hline$K_{D E, A}$ & $\mathrm{~mL} \mathrm{~mol}^{-1}$ & $1.2750 \pm 0.002$ & $10.014 \pm 0.394$ & $0.0002 \pm 0.000$ \\
\hline$K_{D M, A}$ & $\mathrm{~mL} \mathrm{~mol}-1$ & $3.6220 \pm 0.004$ & - & - \\
\hline$K_{T M, A}$ & $\mathrm{~mL} \mathrm{~mol} \mathrm{~m}^{-1}$ & $102.00 \pm 1.834$ & $63.565 \pm 0.985$ & $25.218 \pm 0.029$ \\
\hline \multicolumn{5}{|c|}{ Trimerization reaction: } \\
\hline$k_{T, i . j}$ & $\mathrm{~L} \mathrm{~mol} \mathrm{~s}^{-1}$ & $3.6272 \pm 0.031$ & $0.0259 \pm 0.001$ & $0.0159 \pm 0.002$ \\
\hline$K_{D E, A}$ & $\mathrm{~mL} \mathrm{~mol}^{-1}$ & $0.5900 \pm 0.003$ & $0.9872 \pm 0.004$ & $1.0291 \pm 0.003$ \\
\hline$K_{D M, A}$ & $\mathrm{~mL} \mathrm{~mol}-1$ & $102.00 \pm 2.941$ & $0.0010 \pm 0.000$ & $0.0012 \pm 0.000$ \\
\hline$K_{T M, A}$ & $\mathrm{~mL} \mathrm{~mol}^{-1}$ & - & $18.0646 \pm 0.783$ & $15.948 \pm 0.894$ \\
\hline
\end{tabular}

$\mathrm{I}=$ the main alternative group: vacant site condition variation. $\mathrm{J}=$ the sub-alternative groups: denominator variation. 
Figure 5 shows the comparison between the kinetic constants calculated from the best fit models and those from the experimental data. This figure indicates high validity of all formulated kinetic models except for the case of the trimerization reaction at $423 \mathrm{~K}$, the formulated model to show a significant deviation from the actual values. The plots between the reaction rate constants obtained from the experimental data and those calculated from the proposed models for the dimerization and trimerization reactions showed the $\mathrm{R}^{2}$ values close to 1, indicating the validity of the proposed models as shown in Figures 6 and 7.
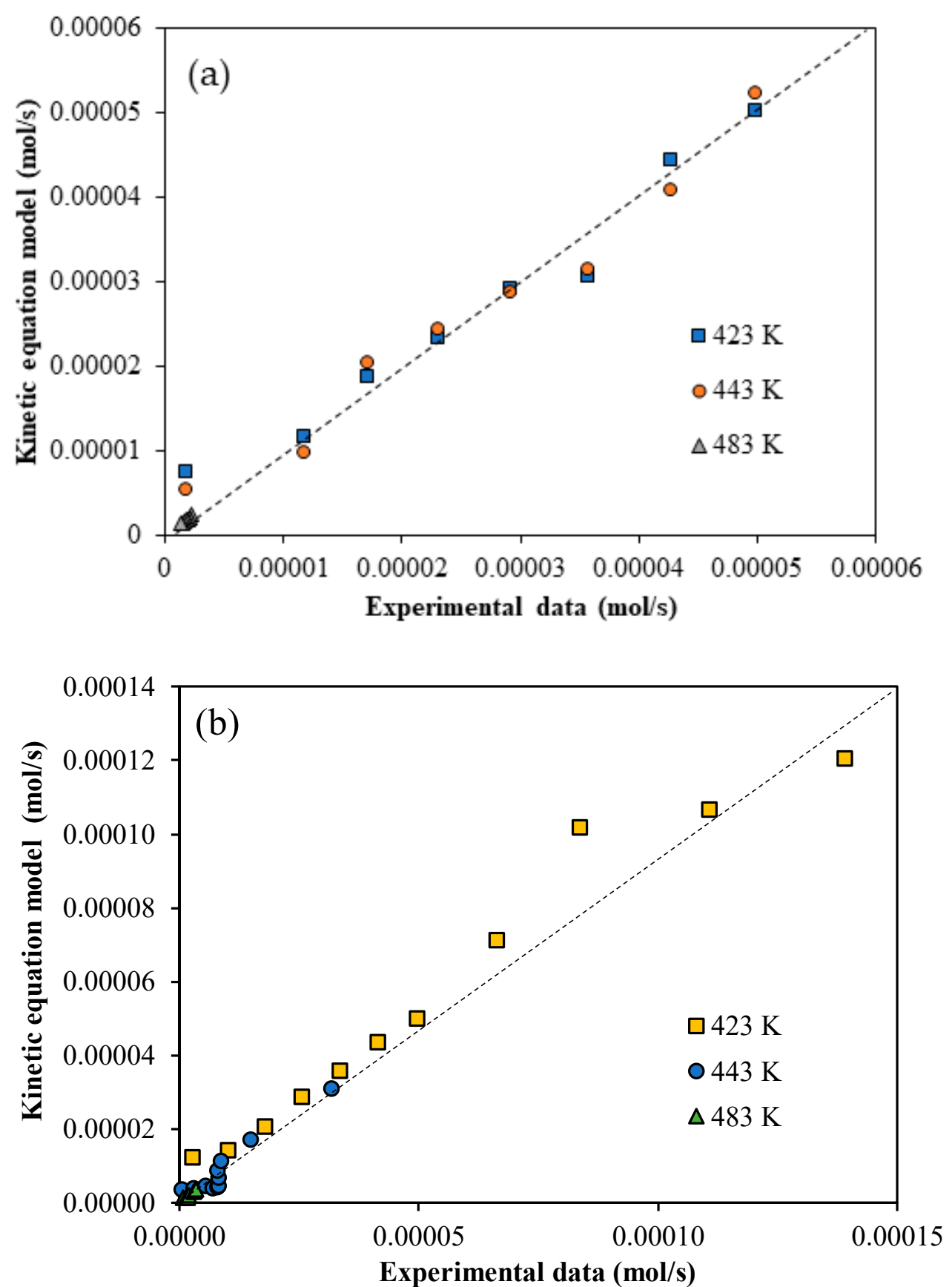

Figure 5. Parity curves of the reaction rate constants obtained from the experimental data and those calculated from the best fit equations for (a) the dimerization reaction and (b) the trimerization reaction. 

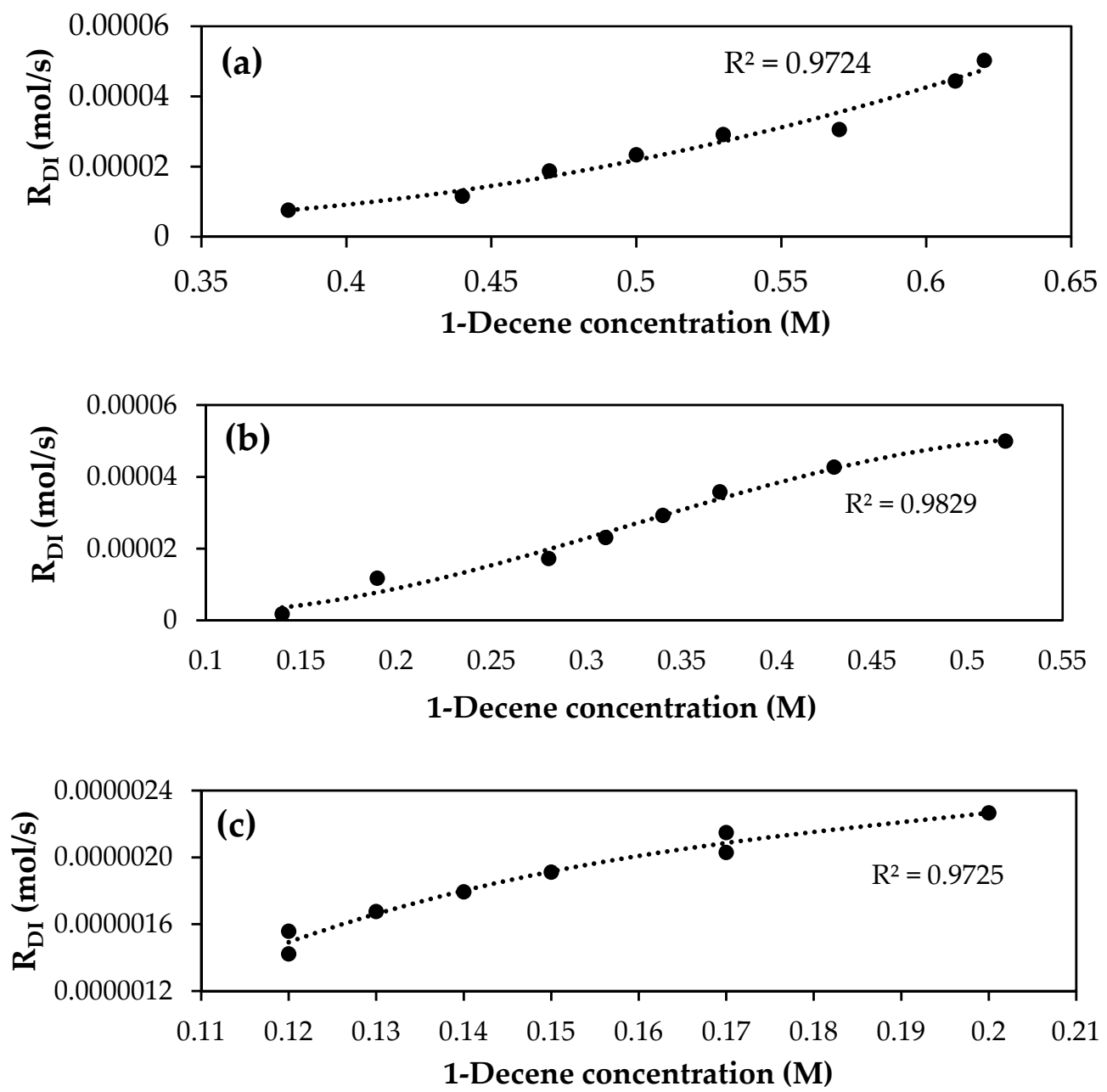

Figure 6. Fitting of the proposed dimerization rate equation with experimental data at (a) $423 \mathrm{~K}$, (b) $443 \mathrm{~K}$ and (c) $483 \mathrm{~K}$. Experimental data are plotted as symbol and calculated data are plotted as dash line.

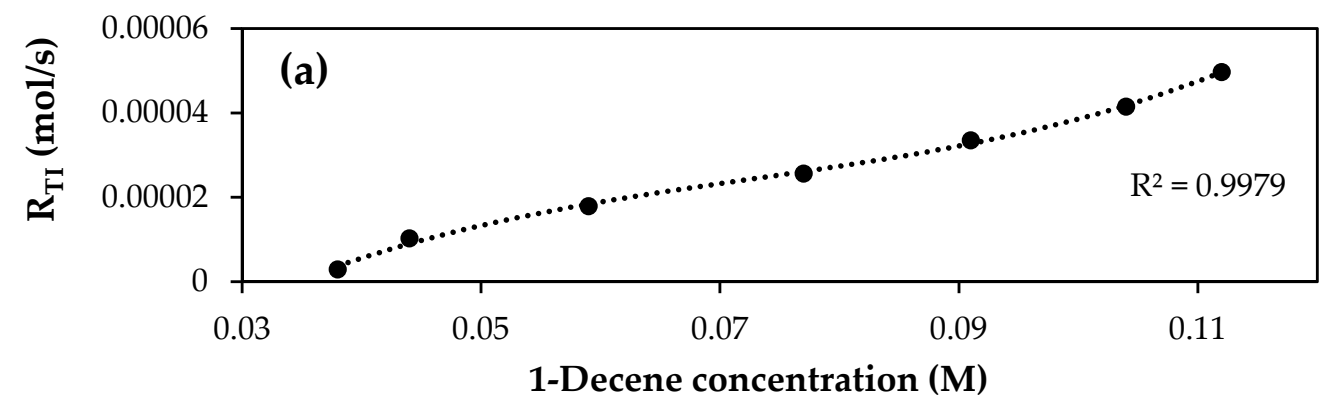

Figure 7. Cont. 

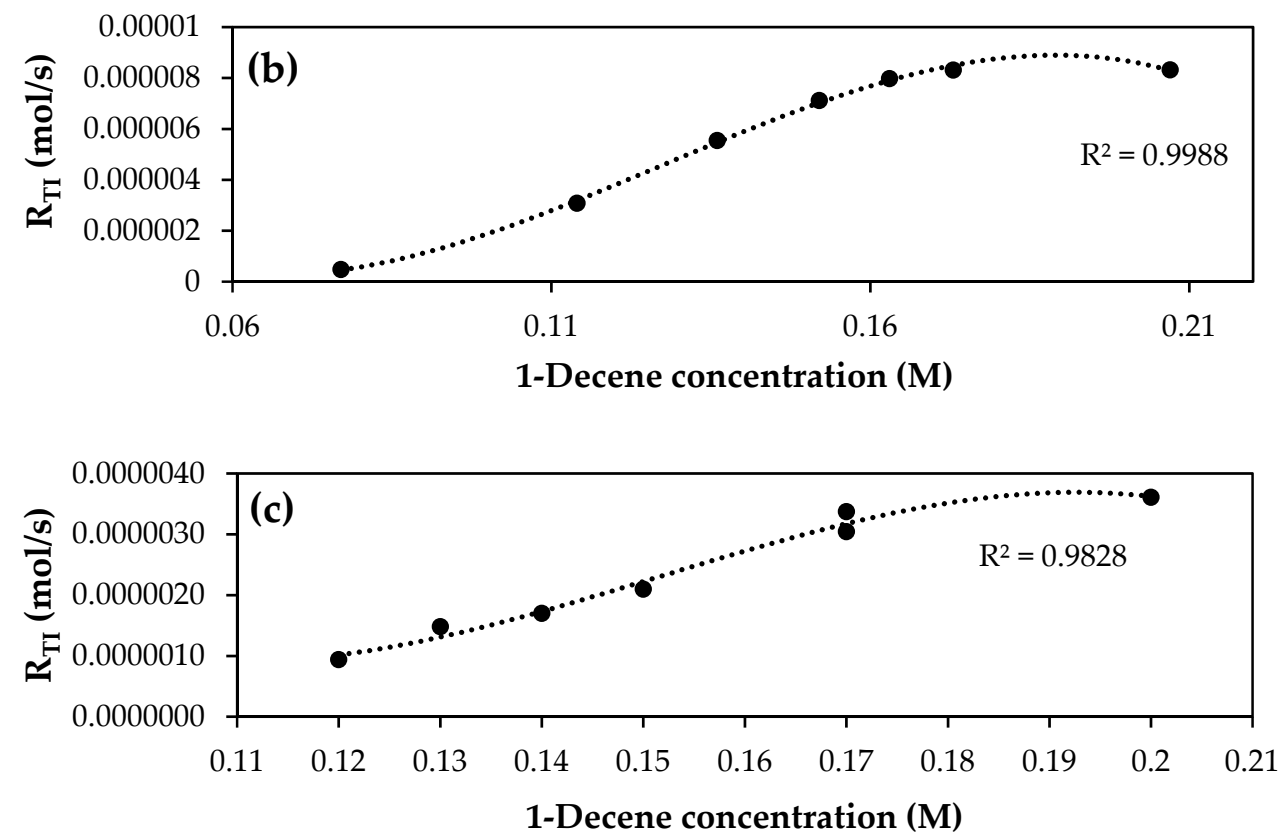

Figure 7. Fitting of the proposed trimerization rate equation with experimental data at (a) $423 \mathrm{~K}$, (b) $443 \mathrm{~K}$ and (c) $483 \mathrm{~K}$. Experimental data are plotted as symbol and calculated data are plotted as dash line.

\section{Experimental Setup}

\subsection{Experimental Setup and Operation}

Figure 8 illustrates the experimental setup of a batch reactor using a $150 \mathrm{~mL}$ three-neck glass connected with a reflux condenser under microwave irradiation as the heating source. The microwave system $(45 \times 45 \times 50 \mathrm{~cm}$ in dimension with multi-mode cavity and doublefeed magnetrons, $2 \times 1000 \mathrm{~W}$ and $2.45 \mathrm{GHz}$ ) was designed to have the ability to control any desired uniform reaction temperature. To enhance the conversion effectiveness of microwave radiation to thermal energy inside the reactor, activated carbon as a microwave receptor was added into the reactor and mixed well with the 1-decene feed [37,38]. For each experiment, a fixed amount of $50 \mathrm{~mL}$ of 1-decene (94\%, Sigma-Aldrich, St. Louis, MO, USA) was added into the reactor with $5 \mathrm{~g}$ of HY zeolite catalyst (CBV700, Zeolyst, Groningen, The Netherlands) and $5 \mathrm{~g}$ of activated carbon (Biocat). The catalyst was heated at $383 \mathrm{~K}$ for $12 \mathrm{~h}$ to remove moisture before use. The reactor was placed into the microwave chamber, and a condenser was attached to the top of the reactor to trap vapors of the 1-decene feed. All products were located outside the microwave unit. Temperature of the condenser circulating water was set at $283 \mathrm{~K}$ using a cool water circulation bath (CTL-901, Siam Zimmerman Ltd., Bangkok, Thailand), and the effects of temperature and time on the oligomerization reaction were investigated at controlled reaction temperatures (423, 443 and $483 \mathrm{~K}$ ). Microwave irradiation was terminated at different reaction time intervals from 10 to $180 \mathrm{~min}$ and the reactor was then allowed to cool down for $60 \mathrm{~min}$. The added catalyst and activated carbon in the mixed liquor samples taken from the reactor were separated by vacuum filtration technique. The clear liquor samples obtained from the vacuum filtration step were further removed from the remaining fractions of 1-decene and $\mathrm{C}_{20}$ hydrocarbon molecules by vacuum distillation at 463 and at $523 \mathrm{~K}$, respectively. The resultant liquid samples after the vacuum distillation step contained $C_{30}$ hydrocarbon and heavier hydrocarbons with a brown and opaque appearance. The fraction of heavier hydrocarbons contained mainly $C_{40}$ with a tiny number of other products. The color of $C_{20}$ hydrocarbon was transparent yellow. Each experiment was repeated three times to obtain average data. The conversion of 1-decene and all products were calculated as percentage weight basis. 


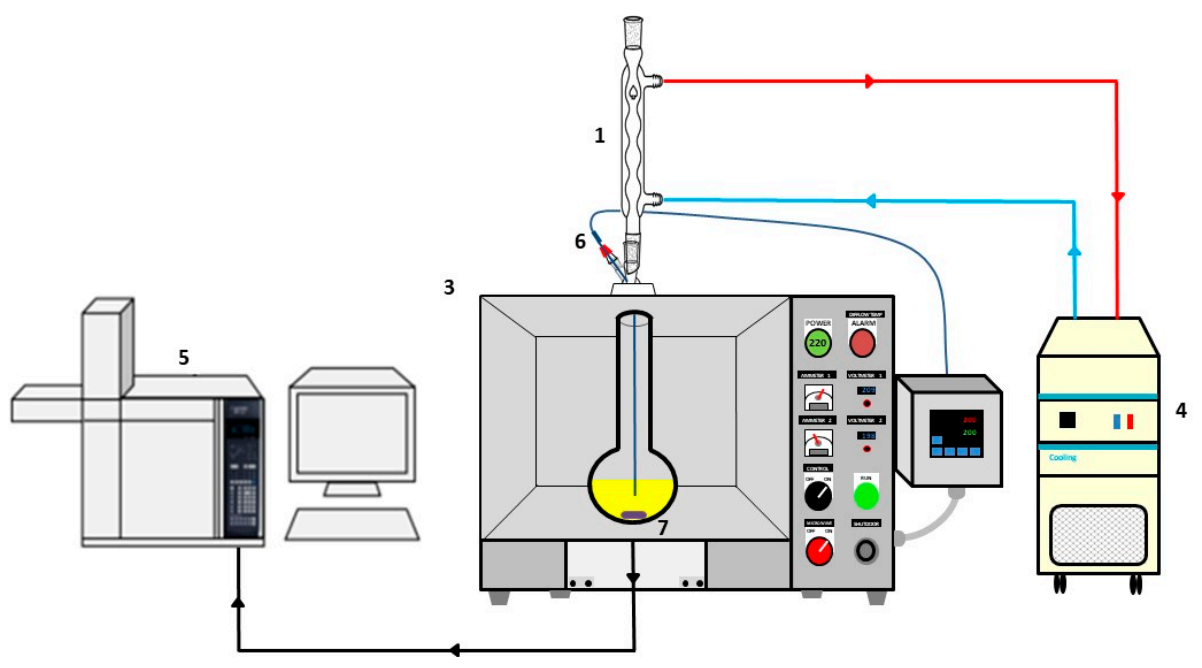

Figure 8. Schematic diagram of oligomerization system for 1-decene: (1) glass reactor; (2) condenser; (3) microwave system; (4) cool water circulator; (5) gas chromatograph; (6) thermocouple probe; (7) magnetic stirrer.

\subsection{Lubricant Product Characterization Techniques}

The structures of oligomers obtained from the reaction experiments on the HY zeolite catalyst were determined using Carbon 13 nuclear magnetic resonance $\left(\mathrm{C}^{13}-\mathrm{NMR}\right)$. A Bruker AVANCE III 400 spectrometer was used to generate a NMR spectra at frequencies of 400 and $100 \mathrm{~Hz}$. The oligomer liquid products were transferred to a glass vial and dissolved in chloroform-D solvent $\left(\mathrm{CDCl}_{3}\right)$. The NMR analysis was focused in the chemical shift range of 5 to $50 \mathrm{ppm}$, representing the carbon and hydrocarbon configurations, respectively. The values of branching ratio and short-chain were calculated by using the peak areas of the $C^{13}$-NMR spectra, as shown in Equations (3) and (4) [16].

$$
\begin{gathered}
\text { Branching ratio }=\frac{15 \times \text { integrated peak area }(11-17 \text { ppm })}{(15 \times \text { integrated peakarea }(11-17 \mathrm{ppm}))+(14 \times \text { integrated peak area }(18-44 \mathrm{ppm}))} \\
\text { Short chain }(\%)=\frac{15 \times \text { integrated peak area }(11-17 \mathrm{ppm})}{\text { Integrated peak area of short chain methyl } \times 100}
\end{gathered}
$$

\subsection{Microkinetics of 1-Decene Oligomerization}

The microkinetics were based on the three sequential steps of adsorption, reaction and desorption with interactions of catalyst active sites and reactant in the solution. Molecular diffusion of the 1-decene reactant from the bulk liquid phase to the surface of the catalyst was neglected because of thorough mixing by the magnetic stirrer. The purpose of microkinetic modeling was to obtain a better understanding of the oligomerization mechanism. Determining the best fit mathematical equation of the reaction rate could be used to simulate industrial production of oligomers over HY zeolite catalyst under microwave irradiation.

In this research, the reactor system was assumed to be an ideal batch type with perfect mixing of catalyst, reactant and products. Hence, the solid catalyst did not have mass transfer limitations and the reactor system was operated under isotherm conditions. Both the adsorption and desorption steps were fast compared with the surface reaction step. The oligomerization reaction includes dimerization to produce a hydrocarbon (HC) with 20 carbon atoms as a dimer, and trimerization to produce an HC with 30 carbon atoms as a trimer. Production of heavier HC molecules can also occur in the presence of strong active catalyst acid sites. Under the studied conditions, the surface reaction was a ratedetermining step since the adsorption and desorption steps were very fast relative to the rate of surface reaction, as confirmed experimentally by a previous study [4]. Formulation 
of the reaction rate equations followed the Eley-Rideal mechanism, which has been widely used for the oligomerization reaction $[39,40]$. The Eley-Rideal expression refers to a single site reaction where the reactant molecules adsorb on the active sites to directly interact with other reactant molecules in the bulk liquid phase or un-adsorbed reactant molecules [41].

For the dimerization reaction, a molecule of 1-decene travels from the reaction medium to a catalyst pore and then diffuses inside the pore. Next, it adsorbs on the active site and then reacts with an unattached molecule of 1-decene to form a dimer. The produced dimer then desorbs from the reaction site, diffuses through the pores of the catalyst and finally moves back to the reaction medium. The trimerization reaction involves two alternative routes. First, an adsorbed 1-decene molecule reacts with two molecules of un-adsorbed 1-decene, and second, an adsorbed dimer further reacts with an un-adsorbed 1-decene molecule to form a molecule of trimer, as shown below:

Surface reactions:

Dimerization reaction

$$
\mathrm{DE}_{\mathrm{A}}+\mathrm{DE} \rightarrow \mathrm{DM}
$$

Trimerization reaction; Alternative I

$$
\mathrm{DE}_{\mathrm{A}}+2 \mathrm{DE} \rightarrow \mathrm{TM}
$$

Trimerization reaction; Alternative II

$$
\mathrm{DM}_{\mathrm{A}}+2 \mathrm{DE} \rightarrow \mathrm{TM}
$$

where

DE-represents a molecule of un-adsorbed 1-decene;

$\mathrm{DE}_{\mathrm{A}}$-represents a 1-decene molecule adsorbing on an active site;

$\mathrm{DM}_{\mathrm{A}}$-represents the dimer adsorbing on an active site;

$\mathrm{DM}$-represents a molecule of dimer to be produced; and

TM-represents a molecule of trimer to be produced.

Adsorption mechanism of 1-decene on an active site:

$$
D E+A \rightleftarrows D E_{A}
$$

where

A-represents the vacant site on the catalyst surface and

$\mathrm{DE}_{\mathrm{A}}$-represents the adsorbed 1-decene.

The adsorption equilibrium equation can be expressed as:

$$
C_{D E_{A}}=K_{D E, A} C_{D E} \theta_{A}
$$

The concentration of vacant sites on the surface of catalyst can be described as:

$$
\theta_{A}=\frac{1}{1+K_{D E, A} C_{D E}+K_{D M, A} C_{D M}+K_{T M, A} C_{T M}}
$$

where

$\theta_{A}$-is the fraction of vacant sites on the catalyst's surface;

$C_{D E}$-is the concentration of 1- decene in the bulk liquid medium;

$C_{D M}$-is the concentration of dimer in the bulk liquid medium;

$C_{T M}$-is the concentration of trimer in the bulk liquid medium;

$C_{D E_{A}}$-is the concentration of 1-decene adsorbing on the active sites;

$K_{D E, A}$-is the adsorption equilibrium constant of 1-decene;

$K_{D M, A}$-is the adsorption equilibrium constant of dimer; and

$K_{T M, A}$-is the adsorption equilibrium constant of trimer.

All reaction rate equations were formulated by assuming that the number of free active sites was small compared to the occupied sites; therefore, the free active sites 
could be neglected. The two main dimerization reaction rate equations are shown in Equations (10) and (12). With the same assumptions, there were four potential groups of possible trimerization reaction rate equations, as shown in Equations (13) to (18).

Dimerization reactions:

$$
\begin{gathered}
R_{D, i}=k_{D, i} K_{D E, A} C_{D E}^{2} \theta_{A} \\
R_{D, 1.1}=\frac{k_{D, 1.1} K_{D E, A} C_{D E}^{2}}{1+K_{D E, A} C_{D E}+K_{D M, A} C_{D M}+K_{T M, A} C_{T M}} \\
R_{D, 2.1}=\frac{k_{D, 2.1} K_{D E, A} C_{D E}^{2}}{K_{D E, A} C_{D E}+K_{D M, A} C_{D M}+K_{T M, A} C_{T M}}
\end{gathered}
$$

Route I-trimerization reactions:

$$
\begin{gathered}
R_{T, i}=k_{T, i} K_{D E, A} C_{D E}^{3} \theta_{A} \\
R_{T, 1.1}=\frac{k_{T, 1.1} K_{D E, A} C_{D E}^{3}}{1+K_{D E, A} C_{D E}+K_{D M, A} C_{D M}+K_{T M, A} C_{T M}} \\
R_{T, 2.1}=\frac{k_{T, 2.1} K_{D E, A} C_{D E}^{3}}{K_{D E, A} C_{D E}+K_{D M, A} C_{D M}+K_{T M, A} C_{T M}}
\end{gathered}
$$

Route II-trimerization reactions:

$$
\begin{gathered}
R_{T, i}=k_{T, i} K_{D M, A} C_{D M} C_{D E} \theta_{A} \\
R_{T, 3.1}=\frac{k_{T, 3.1} K_{D M, A} C_{D M} C_{D E}}{1+K_{D E, A} C_{D E}+K_{D M, A} C_{D M}+K_{T M, A} C_{T M}} \\
R_{T, 4.1}=\frac{k_{T, 4.1} K_{D M, A} C_{D M} C_{D E}}{K_{D E, A} C_{D E}+K_{D M, A} C_{D M}+K_{T M, A} C_{T M}}
\end{gathered}
$$

where

$k_{D, i}$-is the rate constant of the dimerization of 1 for model $R_{D, i} ;$

$k_{T, i}$-is the rate constant of the dimerization of 1 for model $R_{T, i}$.

Table 3 shows the proposed reaction rate equations of the oligomerization. For the first case, all molecules of 1-decene and both the products (dimer and trimer) can adsorb on the active sites of the HY zeolite catalyst. For the second case, because of the very narrow pore structure of the HY zeolite catalyst, trimers cannot be formed on the strong acid sites inside the pores of the catalyst. Therefore, the adsorption equilibrium of trimer product $\left(K_{T M, A}\right)$ can be omitted. For the third case, 1-decene and the trimer can adsorb on the active sites, except for the dimer. For the fourth case, the dimer and trimer cannot adsorb on the active sites, except for 1-decene. 
Table 3. All proposed reaction rate equations for the dimerization and trimerization reactions from 1-decene over the HY zeolite catalyst under microwave irradiation.

\begin{tabular}{|c|c|c|c|c|}
\hline \multirow{2}{*}{ Alternatives } & \multirow{2}{*}{ Dimerization Reaction Equations } & \multicolumn{2}{|c|}{ Trimerization Reaction Equations } & \multirow[t]{2}{*}{ Additional Assumption } \\
\hline & & Alternative I & Alternative II & \\
\hline \multirow{2}{*}{$\begin{array}{l}\text { Case I: } \\
\text { All compounds can } \\
\text { adsorb on the active } \\
\text { sites. }\end{array}$} & $R_{D, 1.1}=\frac{k_{D, 1.1} K_{D E, A} C_{D E}^{2}}{1+K_{D E, A} C_{D E}+K_{D M, A} C_{D M}+K_{T M, A} C_{T M}}$ & $\begin{array}{c}R_{T, 1.1}= \\
\frac{k_{T, 1.1} K_{D E, A} C_{D E}^{3}}{1+K_{D E, A} C_{D E}+K_{D M, A} C_{D M}+K_{T M, A} C_{T M}}\end{array}$ & $\begin{array}{c}R_{T, 3.1}= \\
\frac{k_{T, 4.1} K_{D M, A} C_{D M} C_{D E}}{1+K_{D E, A} C_{D E}+K_{D M, A} C_{D M}+K_{T M, A} C_{T M}}\end{array}$ & - \\
\hline & $R_{D, 2.1}=\frac{k_{D, 2.1} K_{D E, A} C_{D E}^{2}}{K_{D E, A} C_{D E}+K_{D M, A} C_{D M}+K_{T M, A} C_{T M}}$ & $R_{T, 2.1}=\frac{k_{T, 2.1} K_{D E, A} C_{D E}^{3}}{K_{D E, A} C_{D E}+K_{D M, A} C_{D M}+K_{T M, A} C_{T M}}$ & $R_{T, 4.1}=\frac{k_{T, 4.1} K_{D M, A} C_{D M} C_{D E}}{K_{D E, A} C_{D E}+K_{D M, A} C_{D M}+K_{T M, A} C_{T M}}$ & $\begin{array}{l}\text { Neglect the vacant active } \\
\text { site. }\end{array}$ \\
\hline \multirow{2}{*}{$\begin{array}{l}\text { Case II: } \\
\text { Trimers cannot adsorb } \\
\text { on the active sites. }\end{array}$} & $R_{D, 1.2}=\frac{k_{D, 1.2} K_{D E, A} C_{D E}^{2}}{1+K_{D E, A} C_{D E}+K_{D M, A} C_{D M}}$ & $R_{T, 1.2}=\frac{k_{T, 1.2} K_{D E, A} C_{D E}^{3}}{1+K_{D E, A} C_{D E}+K_{D M, A} C_{D M}}$ & $R_{T, 3.2}=\frac{k_{T, 3.2} K_{D M, A} C_{D M} C_{D E}}{1+K_{D E, A} C_{D E}+K_{D M, A} C_{D M}}$ & - \\
\hline & $R_{D, 2.2}=\frac{k_{D, 2.2} K_{D E, A} C_{D E}^{2}}{K_{D E, A} C_{D E}+K_{D M, A} C_{D M}}$ & $R_{T, 2.2}=\frac{k_{T, 2.2} K_{D E, A} C_{D E}^{3}}{K_{D E, A} C_{D E}+K_{D M, A} C_{D M}}$ & $R_{T, 4.2}=\frac{k_{T, 4.2} K_{D M, A} C_{D M} C_{D E}}{K_{D E, A} C_{D E}+K_{D M, A} C_{D M}}$ & $\begin{array}{l}\text { Neglect the vacant active } \\
\text { site. }\end{array}$ \\
\hline \multirow{2}{*}{$\begin{array}{l}\text { Case III: } \\
\text { Dimers cannot adsorb } \\
\text { on the active sites. }\end{array}$} & $R_{D, 1.3}=\frac{k_{D, 1.3} K_{D E, A} C_{D E}^{2}}{1+K_{D E, A} C_{D E}+K_{T M, A} C_{T M}}$ & $R_{T, 1.3}=\frac{k_{T, 1.3} K_{D E, A} C_{D E}^{3}}{1+K_{D E, A} C_{D E}+K_{T M, A} C_{T M}}$ & $R_{T, 3.3}=\frac{k_{T, 3.3} K_{D M, A} C_{D M} C_{D E}}{1+K_{D E, A} C_{D E}+K_{T M, A} C_{T M}}$ & - \\
\hline & $R_{D, 2.3}=\frac{k_{D, 2.3} K_{D E, A} C_{D E}^{2}}{K_{D E, A} C_{D E}+K_{T M, A} C_{T M}}$ & $R_{T, 2.3}=\frac{k_{T, 2.3} K_{D E, A} C_{D E}^{3}}{K_{D E, A} C_{D E}+K_{T M, A} C_{T M}}$ & $R_{T, 4.3}=\frac{k_{T, 4.3} K_{D M, A} C_{D M} C_{D E}}{K_{D E, A} C_{D E}+K_{T M, A} C_{T M}}$ & $\begin{array}{l}\text { Neglect the vacant active } \\
\text { site. }\end{array}$ \\
\hline \multirow{2}{*}{$\begin{array}{l}\text { Case IV: } \\
\text { Only 1-decene adsorbs } \\
\text { on the active sites. }\end{array}$} & $R_{D, 1.4}=\frac{k_{D, 1.4} K_{D E, A} C_{D E}^{2}}{1+K_{D E, A} C_{D E}}$ & $R_{T, 1.4}=\frac{k_{T, 1.4} K_{D E, A} C_{D E}^{3}}{1+K_{D E, A} C_{D E}}$ & $R_{T, 3.4}=\frac{k_{T, 3.4} K_{D M, A} C_{D M} C_{D E}}{1+K_{D E, A} C_{D E}}$ & - \\
\hline & $R_{D, 2.4}=\frac{k_{D, 2.4} K_{D E, A} C_{D E}^{2}}{K_{D E, A} C_{D E}}$ & $R_{T, 2.4}=\frac{k_{T, 2.4} K_{D E, A} C_{D E}^{3}}{K_{D E, A} C_{D E}}$ & $R_{T, 4.4}=\frac{k_{T, 4.4} K_{D M, A} C_{D M} C_{D E}}{K_{D E, A} C_{D E}}$ & $\begin{array}{l}\text { Neglect the vacant active } \\
\text { site. }\end{array}$ \\
\hline
\end{tabular}




\subsection{Solving Kinetic Equation}

Kinetic coefficient and constants were obtained by performing a non-linear regression method on the proposed kinetic equation. Specifically, the Levenberg-Marquardt (LM) algorithm was employed to derive the parameter values. This algorithm is in the form of an objective function with a built-in parameter to minimize the sum of squares of the errors between the experimental and calculated data. All rate constants and coefficients derived from at least 3 experimental trails were used to calculate the standard deviation of the data, as shown in Equation (19)

$$
\text { Standard deviation }=\sqrt{\frac{\sum|x-\mu|}{N}}
$$

where $x$ is kinetic coefficient derived from best-fitted model, $\mu$ is the mean of the kinetic coefficient derived from best-fitted model and $N$ is the number of experimental trials.

\subsection{Verification of Proposed Kinetic Equations}

Model evaluation criteria is usually employed to verify competing kinetic models based on experimental data. The Akaike Information Criterion (AIC) was employed to test all proposed kinetic models by fitting with experimental data to determine the AIC score. One of the main advantages of the AIC method is that it can be used to rapidly evaluate many different models by using marginal likelihood data. AIC calculates the KullbackLeibler $(\mathrm{K}-\mathrm{L})$ divergence presented in two or more alternative probability distribution data.

The kinetic expression with the lowest AIC score indicating the best-fit model was used to simulate the oligomerization reaction over the HY zeolite catalyst. The level of fitness $(\triangle \mathrm{AIC})$ was calculated by subtracting the minimum AIC value of each reaction equation. Any candidate model having AIC $<2$ was considered as valid, $4<\Delta \mathrm{AIC}<7$ was considered as less valid, while $\triangle \mathrm{AIC}>7$ was unacceptable. The equations for determining the AIC value and level of fitness or $\triangle \mathrm{AIC}$ are shown below [32,33].

$$
\begin{gathered}
A I C=n \log \left(\frac{\sum \epsilon_{i}^{2}}{n}\right)+2 K \\
\Delta \mathrm{AIC}=A I C-A I C_{\text {minimum }}
\end{gathered}
$$

where

$n$-is the number of experimental data;

$\epsilon_{i}$-is the residual between experimental data and calculated data;

$\mathrm{K}$ - is the number of predicted constants; and

$A I C_{\text {minimum }}$-is the lowest value of AIC calculated with a specific group of group of equation models.

\section{Conclusions}

The oligomerization of 1-decene over an HY zeolite catalyst under microwave irradiation to produce designed oligomer products for lubricant application was investigated. Optimum conditions for the production of lubricant products were $483 \mathrm{~K}$ and $150 \mathrm{~min}$ to yield $80 \%$ conversion of 1 -decene with $54.2 \%$ dimer, $22.3 \%$ trimer and $3.4 \%$ heavier products. The AIC evaluation results indicated that the best fit model for dimerization was based on the exclusion of vacant sites. The formation of trimer occurred through the interaction between adsorbed dimer and un-adsorbed 1-decene. Calculated apparent activation energies of dimerization and trimerization from 1-decene were $70.8 \pm 0.8$ and $83.6 \pm 0.9 \mathrm{~kJ} / \mathrm{mol}$, respectively. The oligomer product synthesized from 1-decene over the HY zeolite catalyst contained a significant portion of highly branched hydrocarbons derived from the isomerization reaction, causing reduction in the viscosity index of the oligomer products. 
Supplementary Materials: The following are available online at https: / www.mdpi.com/article/ 10.3390/catal11091105/s1, Figure S1: Different dimerization kinetic models at different reaction temperatures using the AIC method; Figure S2: Comparison different trimerization kinetic equation models at different reaction temperatures using the AIC method.

Author Contributions: Conceptualization, project administration, funding acquisition, investigation, validation, visualization, supervision, data analysis, M.S.; investigation, M.S. and S.E., methodology and resources, C.A.; Writing-original draft, S.E.; Writing-review \& editing, M.S. and S.C. All authors have read and agreed to the published version of the manuscript.

Funding: This research received no external funding.

Acknowledgments: The authors gratefully acknowledge the financial support provided by Thammasat University Research Fund (Contract No. 1/2562).

Conflicts of Interest: The authors declare no conflict of interest.

\section{References}

1. Echaroj, S.; Santikunaporn, M.; Chavadej, S. Oligomerization of 1-decene over sulfated alumina catalysts for the production of synthetic fuels and lubricants: Modelling and verification. React. Kinet. Mech. Catal. 2017, 121, 629-644. [CrossRef]

2. Shamiri, A.; Chakrabarti, M.H.; Jahan, S.; Hussain, M.A.; Kaminsky, W.; Aravind, P.V.; Yehye, W.A. The Influence of Ziegler-Natta and Metallocene Catalysts on Polyolefin Structure, Properties, and Processing Ability. Materials 2014, 7, 5069-5108. [CrossRef] [PubMed]

3. Nifant'ev, I.; Ivchenko, P. Fair Look at Coordination Oligomerization of Higher $\alpha$-Olefins. Polymers 2020, 12, 1082. [CrossRef]

4. Techopittayakul, T.; Echaroj, S.; Santikunaporn, M.; Asavatesanupap, C.; Chen, Y.H.; Yuan, M.H. Kinetic modeling of 1-decene oligomerization to synthetic fuels and base oil over tungstated-zirconia catalyst. React. Kinet. Mech. Catal. 2019, 126, 529-546. [CrossRef]

5. Echaroj, S.; Santikunaporn, M.; Chavadej, S. Transformation of Bioderived 1-Decanol to Diesel-like Fuel and Biobased Oil via Dehydration and Oligomerization Reactions. Energy Fuels 2017, 31, 9465-9476. [CrossRef]

6. Marakatti, V.S.; Gaigneaux, E.M. Alkylation of resorcinol with tertiary butanol over zeolite catalysts: Shape selectivity vs. acidity. Catal. Commun. 2021, 152, 106291. [CrossRef]

7. Romero, D.; Rohling, R.; Meng, L.; Rigutto, M.; Hensen, E.J.M. Shape selectivity in linear paraffins hydroconversion in 10membered-ring pore zeolites. J. Catal. 2021, 394, 284-298. [CrossRef]

8. Castro, C.; Shyu, H.; Xaba, L.; Bair, R.; Yeh, D. Performance and onsite regeneration of natural zeolite for ammonium removal in a field-scale non-sewered sanitation system. Sci. Total. Environ. 2021, 776, 145938. [CrossRef] [PubMed]

9. Karimi, S.; Sadjadi, S.; Bahri-Laleh, N.; Nekoomanesh-Haghighi, M. New less-toxic halloysite-supported ionic liquid/ $\mathrm{AlCl}_{3}$ oligomerization catalysts: A comparative study on the effects of various ionic liquids on the properties of polyalphaolefins. Mol. Catal. 2021, 509, 111648. [CrossRef]

10. Rahbar, A.; Bahri-Laleh, N.; Nekoomanesh-Haghighi, M. Microstructural study on low viscosity poly- $\alpha$-olefin oils synthesized via $\mathrm{AlCl}_{3} / \mathrm{H}_{2} \mathrm{O}$ cationic system in the present of xylene and heptane solvents. Fuel 2021, 302, 121111. [CrossRef]

11. Hemmat Esfe, M.; Abbasian Arani, A.A.; Esfandeh, S. Improving engine oil lubrication in light-duty vehicles by using of dispersing MWCNT and ZnO nanoparticles in 5W50 as viscosity index improvers (VII). Appl. Therm. Eng. 2018, 143, 493-506. [CrossRef]

12. Zhang, W.; Wu, J.; Yu, S.; Shen, Y.; Wu, Y.; Chen, B.; Nie, K.; Zhang, X. Modification and synthesis of low pour point plant-based lubricants with ionic liquid catalysis. Renew. Energy 2020, 153, 1320-1329. [CrossRef]

13. Muraza, O. Maximizing Diesel Production through Oligomerization: A Landmark Opportunity for Zeolite Research. Ind. Eng. Chem. Res. 2015, 54, 781-789. [CrossRef]

14. Wang, Q.; Guan, S.; Shen, D. Experimental and Kinetic Study on Lignin Depolymerization in Water/Formic Acid System. Int. J. Mol. Sci. 2017, 18, 2082. [CrossRef]

15. Kamal, S.; Mahajani, S. Kinetic study for oligomerization of acetaldehyde over cation exchange resin. Appl. Catal. A Gen. 2020, 608, 117841. [CrossRef]

16. Afreen, G.; Pathak, S.; Upadhyayula, S. Gas phase alkylation of biomass-derived m-cresol with iso-propanol over zinc modified HY zeolite: Elucidating reaction mechanism and kinetics including deactivation. Chem. Engin. J. 2020, 400, 125824. [CrossRef]

17. Antunes, B.M.; Rodrigues, A.; Lin, Z.; Portugal, I.; Silva, C.M. Alkenes oligomerization with resin catalysts. Fuel Process. Technol. 2015, 138, 86-99. [CrossRef]

18. Reinoso, D.M.; Boldrini, D. Kinetic study of fuel bio-additive synthesis from glycerol esterification with acetic acid over acid polymeric resin as catalyst. Fuel 2019, 264, 116879. [CrossRef]

19. Dagle, V.L.; Lopez, J.S.; Cooper, A.; Luecke, J.; Swita, M.; Dagle, R.A.; Gaspar, D. Production and fuel properties of iso-olefins with controlled molecular structure and obtained from butene oligomerization. Fuel 2020, 277, 118147. [CrossRef]

20. Jin, F.; Zhang, P.; Wu, G. Fundamental kinetics model of acidity-activity relation for ethylene oligomerization and aromatization over ZSM-5 zeolites. Chem. Eng. Sci. 2021, 229, 116144. [CrossRef] 
21. Gou, M.-L.; Cai, J.; Song, W.; Liu, Z.; Ren, Y.-L.; Pan, B.; Niu, Q. Coking and deactivation behavior of ZSM-5 during the isomerization of styrene oxide to phenylacetaldehyde. Chem. Catal. Commun. 2017, 98, 116-120. [CrossRef]

22. Díaz, M.; Epelde, E.; Valecillos, J.; Izaddoust, S.; Aguayo, A.T.; Bilbao, J. Coke deactivation and regeneration of HZSM-5 zeolite catalysts in the oligomerization of 1-butene. Appl. Catal. B Environ. 2021, 291, 120076. [CrossRef]

23. Kwon, M.-H.; Chae, H.-J.; Park, M.B. Oligomerization of 1-hexene over designed SBA-15 acid catalysts. J. Ind. Eng. Chem. 2018, 65, 397-405. [CrossRef]

24. Granollers, M.; Izquierdo, J.F.; Fité, C.; Cunill, F. Kinetic study of methyl-butenes dimerization and trimerization in liquid-phase over a macroreticular acid resin. Chem. Engin. J. 2013, 234, 266-275. [CrossRef]

25. Cruz, V.; Izquierdo, J.; Cunill, F.; Tejero, J.; Iborra, M.; Fité, C.; Bringué, R. Kinetic modelling of the liquid-phase dimerization of isoamylenes on Amberlyst 35. React. Funct. Polym. 2006, 67, 210-224. [CrossRef]

26. Mlinar, A.N.; Zimmerman, P.M.; Celik, F.E.; Head-Gordon, M.; Bell, A.T. Effects of Brønsted-acid site proximity on the oligomerization of propene in H-MFI. J. Catal. 2012, 288, 65-73. [CrossRef]

27. Yue, C.; Liu, C.; Mezari, B.; Brückner, A.; Pidko, E.; Rigutto, M.S.; Hensen, E.J. The nature of strong Brønsted acidity of Ni-SMM clay. Appl. Catal. B Environ. 2016, 191, 62-75. [CrossRef]

28. Liu, C.; Tranca, I.; van Santen, R.A.; Hensen, E.J.M.; Pidko, E.A. Scaling Relations for Acidity and Reactivity of Zeolites. J. Phys. Chem. C 2017, 121, 23520-23530. [CrossRef] [PubMed]

29. Jin, F.; Fan, Y.; Yuan, M.; Min, F.; Wu, G.; Ding, Y.; Froment, G.F. Single-event kinetic modeling of ethene oligomerization on ZSM-5. Catal. Today 2018, 316, 129-141. [CrossRef]

30. Kobayashi, M.; Saitoh, M.; Ishida, K.; Yachi, H. Viscosity Properties and Molecular Structure of Lube Base Oil Prepared from Fischer-Tropsch Waxes. J. Jpn. Pet. Inst. 2005, 48, 365-372. [CrossRef]

31. Moon, S.; Chae, H.-J.; Park, M.B. Oligomerization of light olefins over ZSM-5 and beta zeolite catalysts by modifying textural properties. Appl. Catal. A Gen. 2018, 553, 15-23. [CrossRef]

32. Fabozzi, F.J.; Focardi, S.M.; Rachev, S.T.; Arshanapalli, B.A. The Basics of Financial Econometrics: Tools, Concepts, and Asset Management Applications; John Wiley \& Sons, Inc.: Hoboken, NJ, USA, 2014.

33. Li, Y.; Zhang, Q.; Wang, L.; Liang, L. An AIC-based approach to identify the most influential variables in eco-efficiency evaluation. Expert Syst. Appl. 2020, 167, 113883. [CrossRef]

34. Olutoye, M.A.; Hameed, B.H. Kinetics and deactivation of a dual-site heterogeneous oxide catalyst during the transesterification of crude jatropha oil with methanol. J. Taibah Univ. Sci. 2016, 10, 685-699. [CrossRef]

35. Bonnin, A.; Pouilloux, Y.; Coupard, V.; Uzio, D.; Pinard, L. Deactivation mechanism and regeneration study of Zn/HZSM-5 catalyst in ethylene transformation. Appl. Catal. A Gen. 2021, 611, 117976. [CrossRef]

36. Murzin, D.Y. Catalyst deactivation and structure sensitivity. Catal. Sci. Technol. 2014, 4, 3340-3350. [CrossRef]

37. Menéndez, J.; Arenillas, A.; Fidalgo, B.; Fernández, Y.; Zubizarreta, L.; Calvo, E.; Bermúdez, J. Microwave heating processes involving carbon materials. Fuel Process. Technol. 2010, 91, 1-8. [CrossRef]

38. Ghosh, R.; Bandyopadhyay, A.R.; Jasra, R.; Gagibhai, M.M. Mechanistic Study of the Oligomerization of Olefins. Ind. Eng. Chem. Res. 2014, 53, 7622-7628. [CrossRef]

39. Ding, X.; Geng, S.; Li, C.; Yang, C.; Wang, G. Effect of acid density of HZSM-5 on the oligomerization of ethylene in FCC dry gas. J. Nat. Gas Chem. 2009, 18, 156-160. [CrossRef]

40. Ghashghaee, M. Heterogeneous catalysts for gas-phase conversion of ethylene to higher olefins. Rev. Chem. Eng. 2017, 34, 595-655. [CrossRef]

41. Wei, Y.; Lei, H.; Zhu, L.; Zhang, X.; Yadavalli, G.; Liu, Y.; Yan, D. Oxygen-Containing Fuels from High Acid Water Phase Pyrolysis Bio-Oils by ZSM-5. Catal. Kinet. Mech. Stud. 2015, 8, 5898-58915. 